\title{
PKM PANTI ASUHAN DI KOTA PEKANBARU UNTUK PENINGKATAN KETERAMPILAN BELAJAR DAN SOFTSKILL (Panti Asuhan Putri Aisiyah dan Panti Asuhan Al Hasanah)
}

\author{
Sri Fitria Retnawaty*, Yeeri Badrun, Yulia Fitri \\ Universitas Muhammadiyah Riau \\ email: fitriretno@umri.ac.id
}

\begin{abstract}
Specifically the problem for orphanage children is that there is still a weak ability to master the learning material quickly (Quantum Learning) and soft skills. The observations at the Orphanage showed that the development of material for mastering rapid learning skills (Quantum Learning) and soft learning was still very little. In addition, the lack of learning media facilities also inhibits the improvement of rapid learning skills (Quantum Learning) and soft skills for the orphanage children. To answer these problems, UMRI collaborated with Putri Aisyiah Orphanage and Al Hasanah Orphanage in community partnership activities in line with the Ristekdikti Program. Both of these Orphanages are in the same area as Muhammadiyah Riau University in Pekanbaru City. Putri Aisyiah Orphanage Pekanbaru was established in 1979 and currently carries 31 people. While the Al-Hasanah Orphanage was established in 2000 and currently carries 90 children. In this program, Quantum Learning and soft skill material have been given the target of increasing the ability to learn quickly and instill character strengthening, ethics. Then the ToT Quantum Learning and Softskill workshop was carried out to the orphanage building teacher. This activity was published in the media and the publication of scientific journals.
\end{abstract}

Keyword: Quantum learning, soft skills, character, ethics

\begin{abstract}
Abstrak
Secara spesifik masalah bagi anak-anak panti asuhan adalah masih lemahnya penguatan kemampuan menguasai bahan pembelajaran secara cepat (Quantum Learning) dan kemampuan softskill. Hasil pengamatan di Panti Asuhan, diperoleh gambaran bahwa pengembangan materi penguasaan kemampuan belajar cepat (Quantum Learning) dan pembelajaran sofskill masih sangat sedikit. Selain itu kurangnya sarana media pembelajaran juga menghambat peningkatan kemampuan belajar cepat (Quantum Learning) dan softskill bagi anak-anak panti tersebut. Untuk menjawab permasalahan tersebut UMRI menjalin kerjasama dengan Panti Asuhan Putri Aisyiah dan Panti Asuhan Al Hasanah dalam kegiatan kemitraan masyarakat yang sejalan dengan Program Ristekdikti. Kedua Panti Asuhan ini berada di wilayah yang sama dengan Universitas Muhammadiyah Riau di Kota Pekanbaru. Panti Asuhan Putri Aisyiah Pekanbaru berdiri semenjak tahun 1979 dan saat ini mengasuh 31 orang. Sedangkan Panti asuhan Al- Hasanah berdiri sejak tahun 2000 dan saat ini mengasuh 90 anak. Dalam program ini telah diberikan pembelajaran Quantum Learning dan materi softskill dengan target meningkatkan kemampuan belajar cepat dan ditanamkan penguatan karakter, etika. Kemudian telah terlaksana workshop ToT Quantum Learning dan Softskill kepada guru pembina panti asuhan. Kegiatan ini dipublikasikan dimedia dan penerbitan jurnal ilmiah.
\end{abstract}

Kata kunci: Quantum learning, softskills, karakter, etika 


\section{PENDAHULUAN}

\section{Analisis Situasi}

Mitra dalam usulan Program Kemitraan Masyarakat ini adalah 2 (dua) Panti Asuhan, yaitu Panti Asuhan Putri Aisyiah Pekanbaru (PAA-1) yang telah berdiri tahun 1979 danPanti Asuhan Al-Hasanah (PAA-2) yang didirikan tahun 2009. PAA-1 beralamat di J1 KH. A Dahlan No. 88a Pekanbaru Riau, dan PAA-2 beralamat di Jln Panca Usaha Ujung depan Blok C-53 Pandau Permai Pekanbaru. Kedua Panti Asuhan ini berada di wilayah yang sama dengan Universitas Muhammadiyah Riau yaitu di Kota Pekanbaru.

Kedua Panti Asuhan ini telah berupaya untuk membina dan mengasuh anak-anak panti yang ada dalam berbagai aspek, diantaranya pembinaan pendidikan, pembinaan jasmani juga pembinaan rohani, baik secara formal maupun informal. Untuk pembinaan Pendidikan, PAA-1 menyerahkan pembinaannya kepada sekolah formal. Saat proposal ini disusun, PAA-1 memiliki 31 anak asuh, 9 orang sedang mengenyam pendidikan SD, 15 orang pendidikan SMP, dan 7 orang pendidikan SMU. Seluruhnya memiliki status siswa di berbagai sekolah formal sesuai dengan tingkatannya. Untuk pembinaan informal, PAA-1 memiliki 4 orang pengasuh dengan tingkat pendidikan sarjana 2 orang dan SMU 2 orang (salah satunya sekaligus sebagai juru masak panti).

Berbeda dengan PAA-1, pada PAA-2 saat ini terdapat 90 anak asuh, 40 anak SD, 40 anak SMP dan 10 anak SMU. Anak asuh pada PAA-2 diasuh oleh 5 orang pengasuh, 3 orang strata-1 dan 2 orang SMU (salah satunya sekaligus sebagai juru masak panti). Untuk pembinaan pendidikan, anak asuh PAA-2 di tingkat SMP dan SD dibina secara formal pada madrasah yang dikelola oleh yayasan PAA-2, sedangkan untuk tingkat SMA menempuh pendidikan SMA di luar panti.

Isu utama pelayanan pendidikan di Panti asuhan adalah keterbatasan jumlah dan latar belakang pendidikan yang dimiliki oleh Pembina pada PAA1 dan PAA-2 yang menjadi kendala dalam melakukan pembinaan di panti. Pendidikan formal yang telah didapat anak asuh dirasakan belum cukup untuk meningkatkan karakter dan kemampuan skill anak asuh dalam menghadapi tingginya tuntutan kualitas SDM saat ini, khususnya untuk menghadapi tantangan kehidupan mereka di masa mendatang. Hal Ini ditunjukkan dari laporan hasil evaluasi belajar yang diberikan oleh sekolah terhadap anak panti yang di survei, menyebutkan bahwa rata-rata anak panti masih perlu pembinaan lanjutan di rumah.

Untuk melakukan pembinaan pendidikan informal lanjutan di panti, cara yang dilakukan oleh PAA-1 dan PAA-2 relatif sama, yaitu dengan cara belajar bersama antar anak asuh dengan metoda pembelajaran yang dirasakan belum mengalami pembaruan sebagaimana telah diterapkan pada sekolah-sekolah swasta dan negeri terpadu dan modern saat ini. Akibatnya metode yang diterapkan ini dirasa kurang memberikan peningkatan kemampuan belajar dan karakter anak asuh panti.

Pendekatan softskill adalah proses pembelajaran dan pembangunan karakter (character building) yang dirancang sedemikian rupa agar anakanak panti asuhan secara aktif dapat membangun kompetensi sikap, pengetahuan, dan keterampilan melalui tahapan kemampuan mengamati, mempertanyakan, mengumpulkan informasi, menalar, dan mengomunikasikan. Pembelajaran ini 
hendaknya dilakukan melalui kegiatankegiatan yang menarik, membangkitkan rasa ingin tahu, memotivasi anak untuk berfikir kritis dan menemukan hal-hal yang baru yang pada akhirnya akan memunculkan pemahaman. Semua proses ini haruslah berada di dalam koridor etika moral, kearifan lokal, pemahaman terhadap kebhinekaan bangsa dan kepedulian terhadap lingkungan hidup.

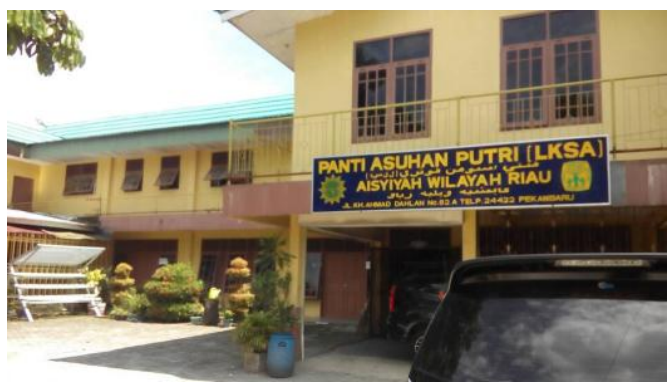

Gambar 1. Fisik Bangunan Panti Asuhan Putri Aisyiyah Pekanbaru

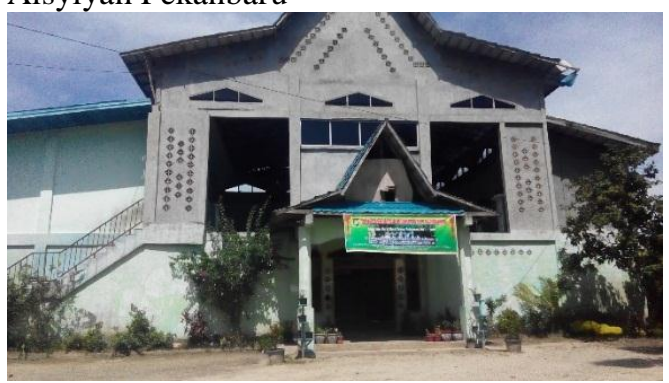

Gambar 2. Fisik Bangunan Panti Al Hasanah Pekanbaru

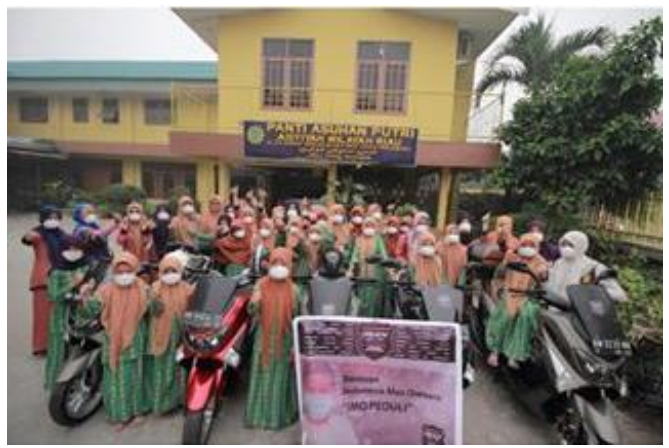

Gambar 3. Anak-anak Panti Asuhan Putri Aisyiyah Pekanbaru

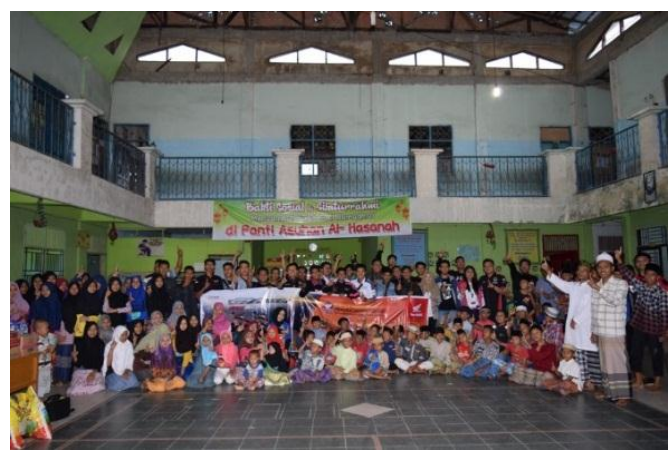

Gambar 4. Anak-anak Panti Asuhan Al Hasanah Pekanbaru

Berdasarkan hal tersebut, pembinaan anak-anak di linkgungan panti asuhan, harus diupayakan agar anak memiliki kesiapan dalam memasuki kehidupan masyarakat yang telah ditanamkan etika moral, kearifan lokal pemahaman terhadap kebhinekaan bangsa dan kepedulian terhadap lingkungan hidup. Dengan penanaman sofskil dalam membentuk karakter anak-anak panti asuhan akan menumbuhkan kretivitas dan kemampuan berfikir kritis yang semuanya akan bermanfaat bagi aktualisasi dan kesiapan anak untuk menghadapi perannya yang lebih luas dan kompleks pada masa yang akan datang di tengah-tengah masyarakat.

\section{Permasalahan Mitra}

Telah dijelaskan sebelumnya bahwa mitra yang menjadi sasaran program ini adalah Panti Asuhan Putri Aisyiah Pekanbaru (PAA-1) dan Panti Asuhan Al-Hasanah (PAA-2). Secara khusus permasalahan prioritas yang dirasakan dan dihadapi oleh pengasuh kedua Panti Asuhan tersebut adalah :

a. Panti Asuhan Putri Aisyiah
Pekanbaru
Panti Asuhan Putri Aisyiah Pekanbaru merupakan Panti Asuhan milik Pimpinan Wilayah Aisyiah. Panti asuhan ini berada di tengah kota pekan baru dengan fasilitas yang cukup memadai dan mendapat cukup bantuan dari berbagai pihak. Panti ini telah 
berdiri sejak tahun 1979. Setiap tahun panti ini mengasuh 30 hingga 40 orang anak asuh dengan 4 orang tenaga asuh.

Hasil wawancara dengan pembina Panti Asuhan Putri Aisyiyah menyebutkan bahwa Panti telah mengupayakan berbagai pembinaan dan peningkatan hardskill dan softskill anak asuh diluar pendidikan formal di sekolah. Program yang dilakukan dikelompokan menjadi 3 kegiatan, yaitu pembinaan Rohani, Pembinaan Keterampilan dan Pembinaan Bahasa.

Kegiatan pembinaan rohani yang dilakukan berupa pembinaan seni baca al-quran, metode IQRA, tahfiz dan Program Muhadoroh. Untuk kegiatan pembinaan keterampilan, anak asuh panti asuhan Putri Aisyiah dilatih Drum Band, Keterampilan merajut, Keterampilan menjahit dan memasak. Pembina untuk kegiatan keterampilan adalah ibu-ibu Pengurus Aisyiah Wilayah Riau. Pembinaan bahasa yang diberikan adalah Les Bahasa Inggris dan Bahasa Arab yang dilakukan oleh guru yang didatangkan dari luar Panti. Seluruh kegiatan pembinaan ini dilakukan rutin mingguan ataupun bulanan. Kedepannya panti asuhan ini memiliki misi untuk menghasilkan anak-anak yatim yang berkualitas, yang memiliki kemampuan bahasa dan keterampilan yang baik.

Akibat perkembangan kurikulum pendidikan yang semakin kompetitif dan kompleks, cenderung memberatkan bagi anak-anak panti yang jauh dari keluarga dan kekurangan dukungan biaya materi serta kasih sayang dari keluarga kandung mereka. Akibatnya anak-anak panti sering merasa jenuh dalam melaksanakan aktivitas belajar mereka.

Hal ini berdampak langsung pada kurangnya atau menurunnya kemampuan belajar mereka, sehingga tidak dapat memenuhi tujuan pendidikan anak panti seperti yang diharapkan. Oleh karena itu pihak pengelola panti mengharapkan adanya upaya dan bantuan dari pihak luar yang dapat mencari dan memilihkan strategi pembelajaran yang lebih bervariasi, inovatif dan meningkatkan skill kemampuan belajar dan daya ingat anak, sehingga anak-anak panti dapat belajar lebih baik dan mengusai pelajaran dengan cepat. Bila itu tercapai akan lebih menumbuhkan kepercayaan diri mereka dan tidak kalah bersaing dengan anak-anak didik yang tidak berasal dari Panti Asuhan

\section{b. Panti Asuhan Al-Hasanah Pekanbaru}

Panti asuhan Al- Hasanah berdiri sejak 17 tahun yang lalu, yaitu pada tahun 2000. Panti ini berada di daerah pinggiran Kota Pekanbaru. Saat ini jumlah anak yang diasuh adalah sebanyak 90 anak dengan 5 orang pembina. Tidak seperti dengan Panti Asuhan Putri Aisyiah, Panti Al Hasanah berada di batas kota atau pinggiran Kota Pekanbaru. Sarana dan prasarana yang ada pada panti asuhan ini masih kurang memadai dan masih sangat membutuhkan bantuan dan uluran tangan dari donatur. Bangunan tempat tinggal, tempat belajar, tempat ibadah dan MCK masih berupa bangunan yang belum selesai dalam pengerjaan ataupun masih semi permanen. Fasilitas belajar berupa kursi, meja dan buku serta penerangan yang ada belum cukup memadai. Kegiatan-kegiatan pengembangan skill anak-anak panti juga masih sangat kurang dan memerlukan perhatian dan bantuan yang lebih intensif.

Pembinaan soft skill dan hard skill yang telah dilakukan oleh pengurus panti masih terbatas pada kegiatan keagamaan berupa baca al-quran dan tahfiz yang langsung di kelola oleh pengurus panti dan ditambah bantuan pembinaan pihak lain berupa kegiatan 
bercocok tanam dan jahit menjahit yang sifatnya masih terbatas dan temporer.

Berdasarkan hasil wawancara dan diskusi dengan pengurus panti, akibat masih lemahnya pembinaan sofskill dan hardsikll di panti asuhan ini mengakibatkan potensi dan kemampuan anak-anak panti belum tergali lebih dalam, kemampuan dan motivasi belajar dirasakan masih sangat rendah. Oleh karena itu pengurus panti sangat mengharapkan adanya bantuan pembinaan khususnya peningkatan kemampuan softskill pembelajaran dan motivasi hidup untuk menatap masa depan yang lebih baik bagi anak-anak panti tersebut.

Dengan adanya peningkatan kemampuan tersebut pengurus panti mengharapkan anak-anak panti dapat mengembangkan diri dan menumbuhkan kepercayaan diri serta karakter diri yang kuat agar bisa lebih mandiri untuk dapat terjun ke masyarakat setelah mereka keluar dari panti nantinya.

\section{Justifikasi Persoalan Prioritas}

Berdasarkan permasalahan yang dihadapi oleh mitra tersebut, maka Universitas Muhammadiyah Riau (UMRI), sebagai perguruan tinggi swasta di Pekanbaru merasa terpanggil dan memiliki kesempatan dan tanggungjawab untuk membantu permasalahan yang dihadapi oleh mitra.

UMRI memiliki 5 orang tenaga ahli yang telah berkecimpung dalam pembinaan softskill mahasiswa sehingga diharapkan dapat melakukan pembinaan softskill dan pembelajaran cepat (Quantum Learning) kepada anak-anak panti dan sekaligus mentransfer keilmuannya kepada pembina panti asuhan. Pembinaan softskill dan pembelajaran cepat (Quantum Learning) akan dilakukan dalam bentuk workshop/Pelatihan intensif, penyediaan media pembelajaran berupa modul dan $\mathrm{CD}$ serta pendampingan dan pengawasan. Selain pendidikan dan pembinaan kepada anak-anak panti, juga dilakukan pelatihan kepada pembina panti untuk dapat terus mengembangkan kemampuan sofskill dan Quantum Learning sekaligus kepada anak-anak panti.

Sehingga dalam program ini disepakati untuk diadakan program antara lain:

1. Pengukuhan kerjasama (MoU) antara UMRI dengan Mitra

2. Penyusunan Materi Pembelajaran Quantum Learning dan Soft Skill yang berbasis etika, moral, kearifan lokal, kebhinekaan bangsa dan pemahaman arti penting kelestarian lingkungan hidup

3. Pengadaan penyediaan media pembelajaran berupa modul dan $\mathrm{CD}$ khusus untuk pelatihan/workshop

4. Pelaksanaan Pembelajaran Quantum Learning dan SoftSkill yang berbasis etika, moral, kearifan lokal, kebhinekaan bangsa dan pemahaman arti penting kelestarian lingkungan hidup

5. Pelatihan untuk bagi pembina panti (Training of Trainer) untuk dapat melanjutkan Pembelajaran Quantum Learning dan Soft Skill kepada anak-anak panti

6. Pengawasan Pelaksanaan

\section{METODE PELAKSANAAN}

\section{Tahapan Pelaksanaan Program}

Program PKM ini akan dilaksanakan selama 8 bulan di 2 Tempat, yaitu di TKN1, dan TK-TIP dengan dengan 5 (lima) tahapan kegiatan pokok. Rincian kegiatan ditampilkan pada tabel berikut.

Tabel 1. Tahapan Kegiatan Program IbM

\begin{tabular}{|l|l|}
\hline Tahapan & Kegiatan \\
\hline I & Persiapan Program \\
\hline & $\begin{array}{l}\text { Pengukuhan Kerjasama (MoU) } \\
\text { antara UMRI dengan Mitra }\end{array}$ \\
\hline II & $\begin{array}{l}\text { Identifikasi dan Penyusunan } \\
\text { Materi Pembelajaran yang tepat }\end{array}$ \\
\hline
\end{tabular}




\begin{tabular}{|l|l|}
\hline & untuk masing-masing panti \\
\hline & $\begin{array}{l}\text { 1. Materi Pembelajaran } \\
\text { Quantum Learning untuk } \\
\text { anak panti }\end{array}$ \\
\hline & $\begin{array}{l}\text { 2. Materi Pembelajaran Softskill } \\
\text { untuk anak panti }\end{array}$ \\
\hline & $\begin{array}{l}\text { 3. Materi Pembelajaran ToT } \\
\text { Quantum Learning dan } \\
\text { Sofstskill untuk Pembina } \\
\text { panti }\end{array}$ \\
\hline III & $\begin{array}{l}\text { Pelaksanaan Kegiatan } \\
\text { Pelatihan/workshop }\end{array}$ \\
\hline & $\begin{array}{l}\text { 1. Pelatihan } \\
\text { Learning }\end{array}$ \\
\hline & 2. Pelatihan Softskill \\
\hline IV & 3. Pelatihan ToT \\
\hline V & Evaluasi dan Monitoring \\
\hline & Pengawasan Pelaksanaan \\
\hline
\end{tabular}

\section{Metoda Pendekatan}

Metoda dalam pelaksanaan kegiatan ini dilakukan melalui beberapa pendekatan yaitu Metode pelatihan dan diskusi kelompok terarah, Metode Praktis (Tindakan), dan Metode Evaluasi.

Metode pelatihan dan diskusi kelompok terarah adalah diskusi terfokus dari suatu anak panti asihan Mitra. Metode ini digunakan untuk melatih kemampuan belajar anak dalam bentuk Quantum learning (seperti 1.

Super memory, 2. Speed Reading dan 3. Mind Maping) dan sofskill unutk menggali dan membahas pembentukan karekter anak, meningkatkan kepercayaan diri, pemahaman akan kebhinekaan bangsa dan kepedulian terhadap lingkungan hidup berbasiskan etika, moral, kearifan lokal, metode ini dilaksanakan dengan panduan tutor. Hasil yang ingin dicapai dari metode ini meningkatnya keterampilan mengingat, membaca, memahami dan menulis bagi Anak Panti, dan anak Panti memiliki pemahaman pentingnya karakter diri, Kepercayaan diri, kebhinekaan bangsa dan kepedulian terhadap lingkungan hidup. Metode ini juga diterapkan kepada Pembina panti dalam bentuk peningkatan pemahaman mereka terhadap Quantum learning dan sofskill untuk dapat dikembangkan dan diterapkan kepada anak-anak panti binaan mereka

Metode tindakan, yaitu tindakan yang bertujuan untuk mengembangkan keterampilan baru atau pendekatan baru dan diterapkan langsung serta dikaji hasil evaluasinya. Penerapan Metode Tindakan dilakukan oleh para anakanak panti dalam situasi-situasi yang diinginkan untuk memperbaiki praktek keterampilan mengingat, membaca, memahami dan menulis serta pembentukan karakter diri, kepercayaan diri, serta pemahaman terhadap kebhinekaan bangsa dan kepedulian terhadap lingkungan hidup. Terdapat dua esensi metode tindakan ini yaitu perbaikan dan keterlibatan peserta.

Hal ini mengarahkan tujuan kegiatan ini ke dalam tiga area yaitu: (1) Untuk memperbaiki teknik belajar anak panti; (2) Untuk pengembangan karakter diri, Kepercayaan diri anak panti; (3) Untuk meningkatkan pemahaman pembina panti terhadap teknik belajar quantum learning dan pembinaan karakter diri, kepercayaan diri, serta pemahaman terhadap kebhinekaan bangsa dan kepedulian terhadap lingkungan hidup bagi anakanak panti.

Metode Evaluasi dilakukan untuk memeriksa proses perjalanan program PKM sekaligus menguraikan faktafakta perubahan yang harus dilakukan di dalam program tersebut. Misalnya adalah keefektifan, efisiensi dan kemenarikan suatu program.

\section{Bentuk Partisipasi Mitra}

Mitra utama program PKM adalah Panti Asuhan Putri Aisyiah Pekanbaru dan Panti Asuhan Al-Hasanah. Kedua mitra ini akan terlibat penuh dalam 
tahapan kegiatan program PKM. Bentuk partisipasi mitra adalah:

1. Menyediakan tempat pelaksanaan kegiatan beserta sarananya dalam pelaksanaan workshop dan pelatihan.

2. Mendatangkan anak panti dalam pelaksanaan worskshop/pelatihan

3. Mendatangkan Pembina panti dalam pelaksanaan ToT Quantum Learning dan Softskill.

4. Bersedia diwawancarai atau mengisi angket dalam rangka pelaksanaan evaluasi keberlanjutan program.

Sedangkan

Universitas

Muhammadiyah Riau (UMRI) menyediakan tenaga ahli, sarana transportasi darat menuju ke lokasi mitra selama program berjalan.

\section{HASIL DAN PEMBAHASAN}

1. Pembelajaran Quantum Learning

Sebelum dilakukan kegiatan pembelajaran Quantum learning dimasing-masing mitra, terlebih dahulu tim pelaksana kegiatan melakukan identifikasi materi yang diperkirakan sesuai dengan kebutuhan masingmasing mitra. Identifikasi materi ini diawali dengan wawancara terbuka dengan masing-masing mitra melalui fasilitas telepon. Data dan informasi yang diperoleh dari masing-masing mitra dirangkum sebagai bahan indentifikasi materi yang akan dirancang nantinya.

Selanjut dengan melalui studi literatur serta berpedoman dari hasil wawancara akan kebutuhan masingmasing mitra maka disusunlah materi yang dianggap dapat memenuhi kebtuhuan pembelajaran quantum learning masing-masing mitra tersebut. Manfaat yang diperoleh dari quantum learning adalah :

1. Sikap positif

2. Motivasi

3. Ketrampilan belajar seumur hidup

4. Kepercayaan diri
5. Sukses

Garis besar materi yang akan disampaikan sebagai berikut:

1. Peta konsep

Peta konsep sebagai teknik belajar efektif. Peta konsep disini lebih menunjukkan pada keuangan ide-ide pikiran sebagai catatan dalam grafis sebagai salah satu teknik belajar efektif. Peta konsep berupa ide pemikiran yang di tuangkan dalam bentuk gambaran atau grafik.

2. Teknik Memori

Memori adalah teknik memasukkan informasi ke dalam otak sesuai dengan cara kerja otak (brain-based technique). Dalam teknik ini perlu meningkatkan efektifitas dan efisiensi otak dalam menyerap dan menyimpan informasi. Teknik yang dilakukan adalah:

1). Melatih Imajinasi,

2) Teknik Rantai Kata,

3) Teknik Plesetan Kata,

4) Sistem Pasak Lokasi,

5) Teknik Akrostik (Jembatan Keledai)

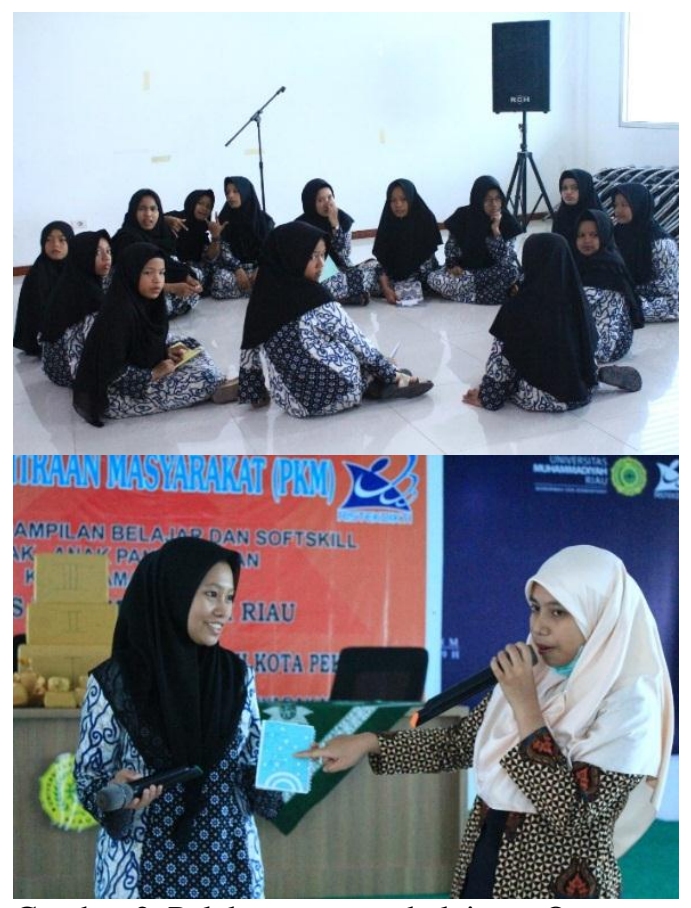

Gambar 2. Pelaksanaan pembelajaran Quantum Learning dan Soft Skills di Panti Asuhan Putri Aisyiah 
Setelah persiapan dirasakan telah sesuai dengan perencanaan, selanjutnya dilakukan pembelajaran Quantum learning di lokasi masing-masing mitra. Kegiatan pembelajaran ini dilakukan dengan mendatangkan trainer yang ahli dibidang quantum learning. Sementara peserta terdiri dari anak-anak panti yang dibina dimasing-msing mitra. Kegiatan ini telah dilaksanakan pada bulan April 2018. Kegiatan ini dilakukan secara terpisah di lokasi masing-msing mitra.

2. Pembelajaran Soft Skill

Selain mempersiapkan kegiatan pembelajaran Quantum learning dimasing-masing mitra, juga dilakukan persiapan pembelajran soft skill untuk anak panti di masing-masing mitra. Rancangan materi yang akan disampikan dalam pembelajaran softskil adalah:

a. Menetapkan Visi Hidup

b. Peningkatan Skill Komunikasi

i. Teknik Pidato,

ii. Teknik presentasi,

iii.Teknik negosiasi,

iv. body language

c. Pembentukan Interpersonal Skill

i. Integritas/kejujuran diri

ii. Keramahan,

Kesopanan, kepedulian, penghargaan dan etika (attitude)

iii.Percaya diri,

iv. Kebijaksanaan dan keadilan

v. Humoris

d. Membangun Team Work dan Managemen Organisasi

e. Membangun Leadership Skill

i. Mengendalikan diri sendiri

ii. Mempengaruhi orang lain

iii.Berfikir Kreatif dan Analitis

iv.Etos Kerja dan Orientasi detail

v. Manajemen Waktu efektif

f. Managemen Stress

Setelah dilakukan pembelajaran Quantum learning di lokasi masingmasing mitra. Selanjutnya dilakukan Kegiatan pembelajaran soft skill.
Kegiatan ini secara langsung dilaksanakan oleh tim pelaksana kegiatan. Kegiatan ini telah dilaksanakan dengan baik pada bulan Juni 2018.

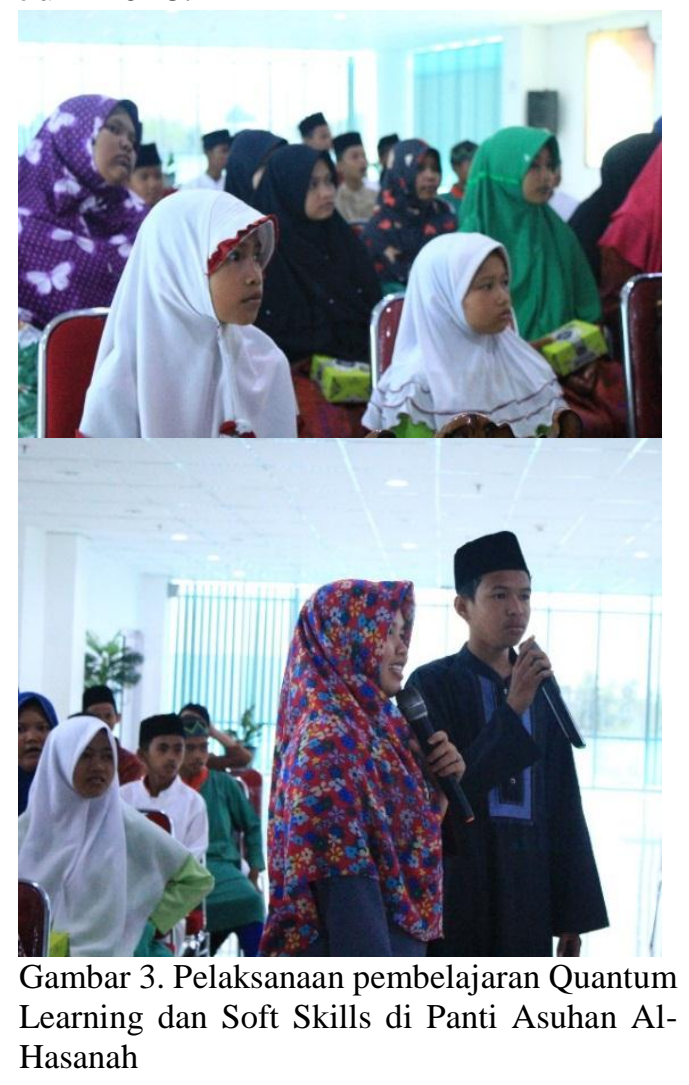

3. Pelaksanaan Training of Trainer Selain memberikan pembelajaran Quantum Learning dan Soft Skill untuk anak-anak panti di masing-masing mitra, kegiatan dalam rangkaian kegiatan ini juga dilakukan pelatihan bagi guru-guru pembina dimasing masing mitra. Materi-materi pelatihan yang berikan tidak terlepas dari materi-materi teknik pelaksanaan pembelajaran Quantum Learning dan soft skill bagi anak-anak panti. Sehingga sepelepas kegiatan ini, guruguru pembina diharapkan dapat melanjutkan kegiatan pembelajara Quantum Learning dan softskil sekaligus mampu mengukur dan mengevaluasi penerapan materi pembelajaran tersebut terhadap anakanak panti. 


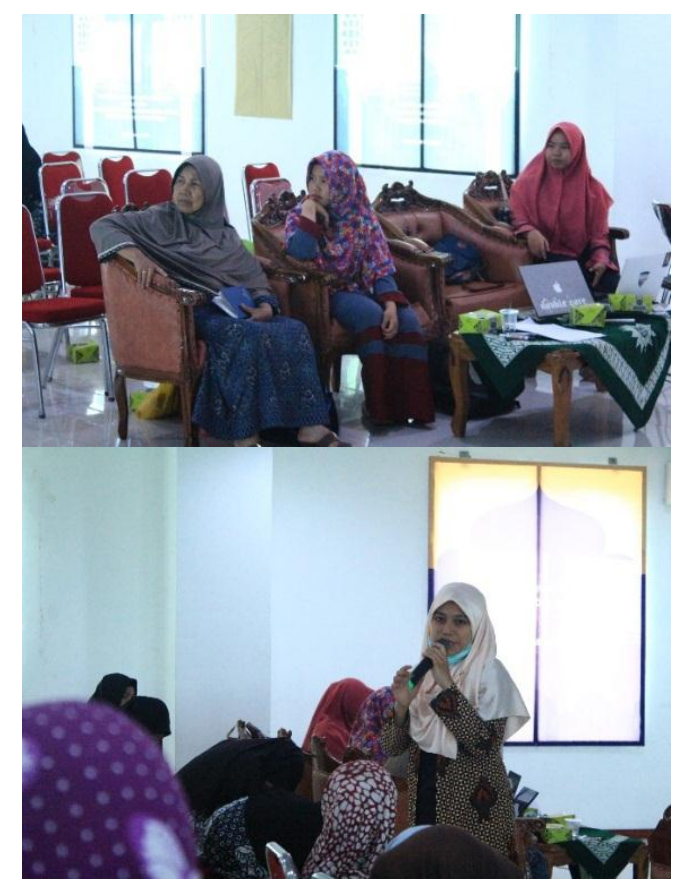

Gambar 4. Pelaksanaan TOT bagi guru-guru pembina Panti Asuhan Putri Aisyiah dan Panti Asuhan Al Hasanah

\section{SIMPULAN}

Kesimpulan yang didapat dari kegiatan Program Kemitraan Masyarakat yang telah dilakukan ini adalah sebagai berikut:

1. Kedua Panti Asuhan yang menjadi mitra masih membutuhkan bantuan dalam peningkatan kualitas etika, moral dan soft skills Pembina dan anak asuh

2. Berbagai metode belajar telah dilaksanakan dikedua mitra tetapi hasil belum efektif

3. Metode belajar Quantum Learning telah dilaksanakan pada kedua mitra. Dan mitra masih membutuhkan training lanjutan untuk pembinaan rutin sehingga lebih terampil

4. Kendala dari pelaksanaan kegiatan ini adalah pengaturan jadwal pelaksanaan kegiatan.

Berdasarkan evaluasi perlu dilakukan training lanjutan untuk pengembangan metode belajar dan soft skills pada panti asuahan lainnya dan masyarakat luas.

\section{UCAPAN TERIMAKASIH}

Terima kasih disampaikan kepada Direktorat Riset dan Pengabdian kepada Masyarakat, Direktorat Jenderal Penguatan Riset dan Pengembangan, Kementerian Riset, Teknologi dan Pendidikan Tinggi sebagai penyandang dana pelaksanaan kegiatan Pengabdian Kepada Masyarakat (PKM) ini tahun anggaran tahun 2018. Terimakasih juga diucapkan kepada Panti Asuhan Putri Aisyiah dan Panti Asuhan Al Hasanah sebagai Mitra Pelaksanaan program PKM ini. 